\title{
Traços da cultura nacional e da cultura de inovação: uma análise dos códigos de ética de empresas brasileiras
}

Traits of the National culture and of the culture of innovation: an analysis of the ethical codes of Brazilian companies

Trazos de la cultura nacional y de la cultura de innovación: un análisis de los códigos de ética de empresas brasileras

(9) Leila Gasparindo

- Mestranda do Programa de Ciências da Comunicação da Escola de Comunicações e Artes da Universidade de São Paulo (ECA-USP)

- Especialista em Gestão Estratégica em Comunicação Organizacional e Relações Públicas pela ECA-USP

- Graduada em Jornalismo pela Pontifícia Universidade Católica de São Paulo (PUC-SP)

- Sócia-fundadora da Trama Comunicação

- Coautora das obras Marketing para incubadoras: o que de bom está acontecendo e Faces do empreendedorismo inovador

- E-mail: Leilag@tramaweb.com.br

(9) Ana Cristina da Costa Piletti Grohs

- Doutoranda do Programa de Ciências da Comunicação da Escola de Comunicações e Artes da Universidade de São Paulo (ECA-USP)

- Mestre em Educação pela Universidade de Sorocaba (Uniso)

- Tem MBA Executivo em Marketing e Comunicação pela Escola Superior de Propaganda e Marketiing (ESPM)

- Bacharel em Comunicação Social - Relações Públicas pela Fundação Armando Álvares Penteado (Faap)

- Licenciada em Pedagogia pela Faculdade Paulista de Educação e Comunicação (Fapec), Ibiúna (SP)

- Autora da obra Entre os fios e o manto: tecendo a inclusão escolar e coautora do livro Gestão estratégica de pessoas: obtendo resultados com a ISO 10015

- E-mail: anacris.piletti@usp.br 


\section{Resumo}

O objetivo do artigo é identificar os traços da cultura nacional e da cultura de inovação nos códigos de ética de empresas brasileiras consideradas como as mais inovadoras pelo Ranking Forbes 2013. Trata-se de uma pesquisa exploratória a partir de estudo bibliográfico e de análise documental dos códigos de éticas de três empresas brasileiras. Verificamos que os códigos de ética podem contribuir para a formação da cultura de inovação. Identificamos que as empresas que mais incentivam os aspectos da cultura de inovação são também aquelas com melhor colocação no ranking Forbes. Consideramos que o estudo contribuiu para a sistematização de um quadro comparativo dos traços da cultura nacional e da cultura de inovação.

\section{PALAVRAS-CHAVE: CULTURA NACIONAL • CULTURA DE INOVAÇÃO • CÓDIGOS DE ÉTICA・COMUNICAÇÃO • EMPRESAS BRASILEIRAS.}

\section{Abstract}

The purpose of the paper is of identifying the traits of National culture and the culture of innovation in the ethical codes of the most innovative Brazilian companies considered by the Forbes 2013 Ranking. This concerns an exploratory study from a bibliographic and documentary analysis of ethical codes of three Brazilian companies. We ascertained that the code of ethics can contribute to the development of an innovation culture. We perceived that the companies that most encourage innovation are those that show the best Forbes rankings. We believe that the study contributed to the systematization of a comparative depiction of the traces of the National culture and innovation culture.

\section{KEYWORDS: NATIONAL CULTURE・CULTURE OF INNOVATION・ETHICAL CODES・COMMUNICATION・BRAZILIAN COMPANIES.}

\section{Resumen}

El propósito del artículo es identificar los trazos de la cultura nacional y de la cultura de innovación en los códigos de ética de las empresas brasileras consideradas las más innovadoras por el Ranking Forbes 2013. Para esto, se realizó una investigación exploratoria a partir de un estudio bibliográfico y de un análisis documental de los códigos de ética de tres empresas brasileras. Verificamos que los códigos de ética pueden contribuir para la formación de la cultura de la innovación. Identificamos que las empresas que más estimulan aspectos de la cultura de innovación son también aquellas con mejor colocación en el ranking Forbes. Consideramos que el estudio contribuye para la sistematización de un cuadro comparativo de los trazos de la cultura nacional y de la cultura de innovación. 
O estímulo à cultura de inovação é um desafio para gestores que buscam maior competitividade no mercado internacional. De maneira geral, inovar significa criar soluções diferenciadas para problemas simples ou complexos. 0 biólogo norteamericano Gregory Pincus, por exemplo, revolucionou a sociedade quando inventou a pílula anticoncepcional na década de 1950. Além de colaborar para o desenvolvimento de políticas públicas que visavam ao controle de natalidade na época, também modificou costumes e valores seculares. Assim, um país ou uma empresa são considerados inovadores quando investem em pesquisas e profissionais dispostos a desenvolver novos métodos ou produtos, assim como promover melhorias em processos organizacionais e descobrir diferentes maneiras de pensar e agir.

O documento The global competitiveness report 2013-2104, que analisou 148 países, mostrou que o Brasil ocupa a 56a posição; na classificação mundial do The global innovation index 2013, o país apareceu em 64ª posição. No Ranking Forbes 2013 das cem empresas mais inovadoras do mundo, apenas três são brasileiras: Natura (10ª posição); o grupo de alimentos e bebidas BRF (390 lugar) e o conglomerado especializado na distribuição de combustíveis e logística Ultrapar Participações (55a posição). Os dados apresentados mostram que ainda falta muito para que o Brasil possa estar mais bem colocado nos rankings de inovação, uma vez que, para conseguir tal objetivo, é preciso que o estado facilite mecanismos para que empresas e cientistas tenham espaço e recursos para criar e inovar.

Diante de tal cenário, uma das possibilidades é pensar que tal posição do Brasil nos rankings tenha a ver com a cultura nacional local. Essa possibilidade está ancorada nos estudos realizados por Geert Hofstede (1980, 1984, 1991), que, após estudar 0 comportamento de mais de sessenta sucursais da IBM no mundo,

encontrou significativas diferenças tanto no comportamento quanto nas atitudes de empregados e executivos da mesma multinacional nos países pesquisados (...) e que a cultura nacional causa mais diferenças e tem mais influência do que a idade, 0 gênero ou a raça" (Hofstede, apud Ferrari, 2011, p. 147).

Assim sendo, vários autores (Ferrari, 2000; Motta e Caldas, 1997; Tanure e Prates, 1997) afirmam que a cultura organizacional está baseada nos elementos da cultura nacional.

Com base nos estudos de Hofstede, o objetivo desse estudo é identificar os traços da cultura nacional e da cultura de inovação em códigos de éticas de empresas brasileiras consideradas as mais inovadoras pelo Ranking Forbes 2013. A pesquisa exploratória utilizou fontes bibliográficas e documentais.

Para uma organização ser considerada uma empresa inovadora, é provável que apresente normas e valores de incentivo à pesquisa e ao desenvolvimento de novas soluções e produtos. Conforme descrito no Manual de Oslo (Finep, 1997), "as empresas podem implementar novas estruturas organizacionais ou novas práticas para introduzir uma nova cultura de negócios, normas e valores com o objetivo de melhorar a capacidade de inovar da empresa" (Finep, 1997, p. 98). Tais normas e valores, para serem praticados, também precisam ser comunicados, sendo um importante instrumento de comunicação para tal finalidade os códigos de ética. Tomando como base que os códigos de ética refletem os elementos da cultura organizacional, foram elaboradas duas questões de pesquisa: Os códigos de ética das empresas reconhecidas como as mais inovadoras apresentam os princípios e valores da cultura de inovação? Será que é possível identificar traços das culturas nacional e organizacional nessas empresas por meio dos códigos de ética? 
Nosso texto está dividido em quatro partes. A primeira apresenta o referencial teórico sobre o processo de comunicação e os códigos de ética; na segunda, abordamos a cultura de inovação e suas características, assim como as culturas nacional e organizacional; na terceira, destacamos os procedimentos metodológicos do estudo; na quarta, procedemos à análise e interpretação dos resultados obtidos.

\section{COMUNICAÇÃO E CÓDIGOS DE ÉTICA}

O sentido etimológico da palavra comunicação é "tornar comum". Como processo social e humano, é por meio da comunicação que indivíduos e grupos compartilham e criam significados. No ambiente organizacional, o processo de comunicação permeia todas as áreas e sua função é tornar-se transversal na estrutura para que possa potencializar a qualidade das informações transmitidas e os relacionamentos estabelecidos.

Estudo coordenado por James Grunig (1992) sugeriu que o contexto organizacional interno pode cultivar ou impedir a gestão da comunicação excelente. Segundo o autor, organizações que praticam uma "comunicação excelente" tendem a apresentar: (1) cultura organizacional participativa; (2) sistema simétrico de comunicação interna; (3) estruturas mais orgânicas; (4) programas que oferecem oportunidades equitativas para homens e mulheres e minorias; (5) aumento de satisfação no trabalho entre os funcionários.

Assim, a estrutura orgânica permite aos funcionários da organização participar das tomadas de decisões contando com um modelo de gestão descentralizado. Grunig et al. (2011) evidenciou que a comunicação simétrica dificilmente ocorre em organizações com estrutura centralizada, hierárquica e de cultura autoritária. Utilizando os princípios de Grunig (1984, 1991), Maria Aparecida Ferrari (2000) constatou que os modelos de comunicação praticados nas empresas são influenciados pelos modelos de gestão e pelos elementos que conformam a cultura organizacional.

Como processo, a comunicação simétrica de mão dupla acontece em ambientes mais participativos nos quais a informação flui com transparência e assertividade. Para que a comunicação se efetive, portanto, as pessoas e organizações dispõem de diversas técnicas e ferramentas, sendo os códigos de ética uma delas. Nas organizações, a implantação de códigos de conduta e ética' ganhou impulso após escândalos envolvendo as ligações de grandes empresas e políticos europeus (Humberg, 2002). No Brasil, principalmente as empresas que aderiram aos processos de governança corporativa, adotaram códigos de conduta e ética.

De acordo com Marina do Amaral Daineze (2004, p. 70), os códigos de ética "atuam como comunicadores da filosofia da organização e como orientadores para ações dos funcionários, a tomada de decisões pela alta administração e as relações das organizações com seus públicos diversos".

Ainda, conforme a autora, o código de ética é um dispositivo no qual a organização expressa as suas expectativas e compromissos com cada um dos seus públicos, oferecendo a eles a liberdade de escolha para segui-lo ou não. Portanto, a adesão aos princípios e valores declarados nos códigos de ética também é influenciada pelos valores e pelas crenças das pessoas e da sociedade. 


\section{CULTURA DE INOVAÇÃO}

\section{Características}

Para entendermos o que é cultura de inovação precisamos compreender o que é cultura e o que é inovação. Os dois termos são repletos de definições. Segundo Hofstede (1991), cultura é uma programação mental, que diferencia um grupo de outros e é partilhada coletivamente. Assim, cultura é o conjunto de princípios, valores, normas, condutas e artefatos compartilhados por determinado grupo considerando a época e o lugar. 0 conceito de inovação também tem evoluído e seu escopo foi ampliado, como pode ser observado nas várias versões do Manual de Oslo(Finep, 1997). A mais recente definição preconiza que inovação é a implementação de uma melhoria significativa ou desenvolvimento de novos produtos (bens ou serviços), processos, método de marketing ou configuração organizacional nas práticas dos negócios, no local de trabalho ou nas relações externas (The Global Innovation Index, 2013).

Renata S. Pereira de Godoy e Dóris Lieth N. Peçanha (2009), no Quadro 1, apresentam diversos estudos recentes (Mavondo e Farrel, 2003; Martins e Terblanche, 2003; Solomon, Winslow e Tarabishy, 2002; Stringer, 2000; e Ahmed, 1998), mostrando que organizações inovadoras têm características culturais distintas das demais:

\section{Quadro 1 - Características da cultura de inovação.}

\begin{tabular}{|c|c|}
\hline Orientação para o mercado & Tempo hábil para o desenvolvimento de tarefas \\
\hline Comunicação clara e aberta & Tolerância ao risco, à ambiguidade e ao conflito \\
\hline Compartilhamento de lucro & Comprometimento e envolvimento dos colaboradores \\
\hline Trabalho desafiante e em equipe & Coesão e reconhecimento intrínseco entre os membros \\
\hline Liderança forte e que oferece suporte & $\begin{array}{l}\text { Existência de critérios claros para } \\
\text { julgamento de sucesso da inovação }\end{array}$ \\
\hline Ênfase no comportamento empreendedor & $\begin{array}{l}\text { Reconhecimento da importância estratégica } \\
\text { da inovação por todo grupo }\end{array}$ \\
\hline Objetivos claros, definidos, compartilhados & $\begin{array}{l}\text { Encorajamento da autonomia dos indivíduos para expressar } \\
\text { opiniões e compartilhar seus conhecimentos }\end{array}$ \\
\hline Reconhecimento a esforços e conquistas & $\begin{array}{l}\text { Estabelecimento, em todos os níveis hierárquicos, } \\
\text { de estratégias que valorize a aquisição, a criação e } \\
\text { acumulação, proteção e exploração do conhecimento }\end{array}$ \\
\hline
\end{tabular}

Fonte: Godoy; Peçanha, 2009, p. 144.

Como pode ser observado no quadro, os autores destacam as características da cultura de inovação e percebemos que 0 modelo de comunicação simétrico de mão dupla (Grunig, 1991) é o mais adequado para ambientes de inovação. No entanto, um importante impacto interno que pode ser gerado nas organizações é o choque entre os valores da cultura de inovação e os da cultura nacional e organizacional. 


\section{Cultura organizacional e cultura nacional}

Como comentamos no início desse texto, Hofstede (1991) realizou uma investigação empírica nas filiais da IBM em mais de sessenta países. Segundo o estudo, as culturas nacionais diferem em cinco dimensões: a) modo de enfrentar a desigualdade e a relação com a autoridade e o poder, ou seja, a distância hierárquica; b) relação do indivíduo e o grupo; c) diferenças entre os papéis sociais masculino/feminino; d) grau de tolerância ao desconhecido na forma de gerir a incerteza; e) orientação de curto versuslongo prazo.

Depois de três décadas, a partir da base de dados e das dimensões definidas por Hofstede, Tanure (2005; 2010) realizou uma comparação entre a gestão brasileira e a gestão na América Latina, nos Estados Unidos, na Europa e na Ásia. Nesse estudo, a autora verificou que "a hierarquia e concentração de poder continuam como fortes dimensões na sociedade brasileira" (Tanure, 2010, p. 42). Essa característica se confronta com alguns valores centrais da cultura de inovação, como, por exemplo, o "encorajamento da autonomia dos indivíduos para expressar opiniões e compartilhar conhecimentos" (Godoy; Peçanha, 2009, p. 14), que destaca a necessidade da descentralização de processos decisórios.

A partir dos resultados de sua pesquisa, Tanure (2005; 2010) elaborou o "Sistema de ação cultural brasileiro", considerando as relações que são estabelecidas entre líderes e liderados nos âmbitos institucional e pessoal. No Quadro 2 apresentamos os resultados da análise conjunta desses quatro subsistemas (líderes, liderados, institucional e pessoal) e os traços da cultura brasileira resultantes dessa análise.

Quadro 2 - Sistema de ação cultural brasileiro.

\begin{tabular}{|c|c|c|c|}
\hline & ESPAÇO INSTITUCIONAL & $\longleftrightarrow$ & ESPAÇO PESSOAL \\
\hline \multirow[b]{2}{*}{ LÍDERES } & Concentração de poder & Paternalismo & Personalismo \\
\hline & $\begin{array}{l}\text { Estrutura hierarquizada, poder } \\
\text { centralizado, protecionismo e } \\
\text { prática autoritária do líder. }\end{array}$ & Autoridade com base no carisma & $\begin{array}{l}\text { Laços pessoais de confiança } \\
\quad \text { e relações informais }\end{array}$ \\
\hline & Ambiguidade/ Formalismo & Flexibilidade & Lealdade às pessoas \\
\hline & $\begin{array}{l}\text { Baixa necessidade de lidar com } \\
\text { as incertezas do futuro }\end{array}$ & $\begin{array}{l}\text { Adaptabilidade e criatividade } \\
\text { para ajustar-se a novos } \\
\text { processos e regras }\end{array}$ & $\begin{array}{l}\text { Ética social baseada na } \\
\text { lealdade e na valorização } \\
\text { das necessidades do líder }\end{array}$ \\
\hline$\downarrow$ & Postura de espectador & Medo de errar & Evitar conflito \\
\hline LIDERADOS & $\begin{array}{l}\text { Aceitação da desigualdade de poder, } \\
\text { do protecionismo e da dependência. }\end{array}$ & $\begin{array}{l}\text { Desejo de acertar sempre e } \\
\text { ser reconhecido pelo líder }\end{array}$ & $\begin{array}{c}\text { Tendência de evitar a confrontação } \\
\text { direta para manter a qualidade } \\
\text { do relacionamento }\end{array}$ \\
\hline
\end{tabular}

Fonte: Adaptado de Tanure (2005; 2010). 
No quadro, destacamos que o protecionismo dos líderes no âmbito institucional gera baixa iniciativa nos liderados e dependência no processo de tomada de decisão. No âmbito pessoal, essas relações são marcadas pelo personalismo por parte dos líderes e uma tendência de evitar o conflito por parte dos liderados. 0 paternalismo dos líderes e o medo de errar por parte dos liderados resultam da intersecção do âmbito institucional e pessoal. Da mesma forma, o traço da ambiguidade nasce das características das relações entre líderes e liderados no espaço institucional, enquanto a lealdade às pessoas surge dessas relações no âmbito pessoal. Nesse sistema, a flexibilidade surge como traço central da cultura brasileira marcada pela adaptabilidade e criatividade, estando esta última característica ligada à capacidade de inovar (Tanure, 2005; 2010).

Alguns traços da cultura organizacional nacional foram ressignificados por Thomaz Wood Jr. e Rebeca Alves Chu (2008) considerando a internacionalização da economia brasileira a partir da década de 1990. 0 jeitinho brasileiro ou flexibilidade marcada pela capacidade de adaptação e criatividade passou a ter conotação negativa para o país, visto como um comportamento pouco profissional ou amador. No entanto, individualmente, essa característica ainda é considerada útil e benéfica. Também o formalismo, que era visto como a valorização de regras e procedimentos burocráticos passou a ser entendido como reconhecimento da importância da adoção de padrões operacionais e gerenciais superiores.

A revisão desses estudos possibilitou identificar que os elementos usados por Tanure (2005), Hofstede (1991) e Wood e Chu (2008) para a definição dos traços culturais que permeiam as organizações brasileiras, são semelhantes e pouco se alteraram, passando apenas por um processo de ressignificação após o início do processo de internacionalização das organizações.

\section{Comunicação, cultura nacional e cultura de inovação}

Após os estudos sobre comunicação e códigos de ética, cultura de inovação e cultura organizacional e nacional, chegamos a três importantes considerações: 1) Como processo, a comunicação simétrica de mão dupla é a mais adequada para a construção de uma cultura de inovação; 2) Como instrumento, os códigos de ética são poderosos canais de comunicação que modelam 0 comportamento nas organizações, chegando até a colaborar com o desenvolvimento da cultura de inovação; 3) Alguns traços da cultura brasileira são incompatíveis com as características da cultura de inovação.

Em uma perspectiva na qual a cultura é entendida como resultado da invenção social que é transmitida mediante o processo de comunicação e aprendizado (Tanure; Prates, 1996), os mecanismos comunicacionais voltados à promoção da cultura de inovação são determinantes. Discutir o estímulo à cultura de inovação no Brasil passa por reconhecer a influência dos traços culturais nacionais e o papel do processo de comunicação nas empresas que buscam competitividade proveniente de inovação. Sendo assim, a partir dos estudos de Godoy e Peçanha (2009), Hofstede (1991), Tanure (2005; 2010) e Wood e Chu (2008), relacionamos cinco categorias relevantes para analisar os traços da cultura nacional e da cultura de inovação nos códigos de éticas de empresas brasileiras que foram consideradas as mais inovadoras pelo Ranking Forbes 2013. 0 Quadro 3 apresenta essas categorias relacionando os traços da cultura nacional e as características da cultura de inovação em cada uma delas. 
Quadro 3 - Comparativo entre cultura nacional e cultura de inovação.

\begin{tabular}{|c|c|c|}
\hline CATEGORIA & CULTURA NACIONAL & CULTURA DE INOVAÇÃO \\
\hline Relações institucionais & \multirow[b]{2}{*}{$\begin{array}{l}\text { - Gestão autoritária } \\
\text { - Alta distância hierárquica } \\
\text { - Centralização de poder } \\
\text { - Desigualdade de poder } \\
\text { - Postura paternalista - líder } \\
\text { - Postura de espectador - liderado } \\
\text { - Transferência ou diluição de } \\
\text { - Responsabilidade } \\
\text { Relação de interdependência } \\
\text { líder/liderado }\end{array}$} & \multirow[b]{2}{*}{$\begin{array}{l}\text { - Gestão participativa } \\
\text { - Baixa distância hierárquica } \\
\text { - Descentralização } \\
\text { - Valorização do conhecimento em todos } \\
\text { níveis hierárquicos } \\
\text { - Trabalho em equipe } \\
\text { - Encorajamento da autonomia } \\
\text { - Comportamento empreendedor } \\
\text { - Comprometimento e envolvimento } \\
\text { - Relação de apoio entre líder e liderado }\end{array}$} \\
\hline $\begin{array}{l}\text { Forma como é organizado e distribuído } 0 \\
\text { poder na organização e as relações formais } \\
\text { estabelecidas entre líderes e liderados. }\end{array}$ & & \\
\hline Relações pessoais & \multirow[b]{2}{*}{$\begin{array}{l}\text { - Personalismo (importância a interesses } \\
\text { pessoais/rede de amigos/parentes em } \\
\text { detrimento de interesses coletivos/ } \\
\text { sociais) } \\
\text { - } \text { Alto grau de confiança em rede de } \\
\text { amigos/parentes para resolução de } \\
\text { problemas } \\
\text { - Obtenção ou distribuição de privilégios }\end{array}$} & \multirow[b]{2}{*}{$\begin{array}{l}\text { - Reconhecimento a esforços e conquistas } \\
\text { - Existência de critérios claros para } \\
\text { julgamento de sucesso da inovação }\end{array}$} \\
\hline $\begin{array}{l}\text { Forma como os indivíduos se relacionam } \\
\text { no cotidiano. }\end{array}$ & & \\
\hline Gestão de conflitos & \multirow{2}{*}{$\begin{array}{l}\text { - Baixa tolerância ao conflito } \\
\text { - Valorização do relacionamento } \\
\text { - Demonstração de emoções e } \\
\text { - } \text { sentimentos } \\
\text { - } \text { Cordialidade - dificuldade de dizer não } \\
\text { - } \text { Medo de errar }\end{array}$} & \multirow[b]{2}{*}{$\begin{array}{l}\text { - Tolerância ao conflito } \\
\text { - Trabalho desafiante e em equipe }\end{array}$} \\
\hline $\begin{array}{l}\text { Forma como são administradas as } \\
\text { negociações, os conflitos e tomada de } \\
\text { decisão. }\end{array}$ & & \\
\hline Comunicação & \multirow{2}{*}{$\begin{array}{l}\text { - } \text { Baixa participação nos processos } \\
\text { decisórios } \\
\text { - Comunicação assimétrica } \\
\text { - Comunicação informal } \\
\text { - } \text { Prolixidade }\end{array}$} & \multirow{2}{*}{$\begin{array}{l}\text { - } \text { Comunicação clara e aberta } \\
\text { - Espaço para expressão de opiniões } \\
\text { - Espaço para comunicação simétrica } \\
\text { - Assertividade }\end{array}$} \\
\hline $\begin{array}{l}\text { Forma como acontecem às interações } \\
\text { e troca de informações significativas na } \\
\text { organização. }\end{array}$ & & \\
\hline Flexibilidade & \multirow{2}{*}{$\begin{array}{l}\text { - Tolerância à quebra de regras } \\
\text { - No nível organizacional, pode ser visto } \\
\text { como comportamento amador } \\
\text { - Criatividade }\end{array}$} & \multirow[b]{2}{*}{$\begin{array}{l}\text { - Reconhecimento da importância da } \\
\text { inovação }\end{array}$} \\
\hline $\begin{array}{l}\text { Forma como pessoas e organização lida } \\
\text { com as mudanças. }\end{array}$ & & \\
\hline
\end{tabular}




\begin{tabular}{|c|c|c|}
\hline CATEGORIA & CULTURA NACIONAL & CULTURA DE INOVAÇÃO \\
\hline Orientação para resultados & \multirow[b]{2}{*}{$\begin{array}{l}\text { - Alto nível de controle de incerteza, } \\
\text { maior necessidade de previsibilidade } \\
\text { das coisas e da existência de leis e } \\
\text { regras } \\
\text { - Reconhecimento da importância } \\
\text { da adoção de padrões operacionais e } \\
\text { gerenciais superiores } \\
\text { - Orientação de curto prazo } \\
\text { - Foco na tarefa e no processo } \\
\text { - Gestão ineficiente do tempo }\end{array}$} & \multirow[b]{2}{*}{$\begin{array}{l}\text { - Tolerância ao risco e ambiguidade } \\
\text { - Orientação para o mercado } \\
\text { - Objetivos claros, definidos e } \\
\text { - } \text { compartilhados } \\
\text { - Toco nos resultados } \\
\text { tarefas }\end{array}$} \\
\hline $\begin{array}{l}\text { Forma como planeja processos, administra } \\
\text { o tempo e lida com o risco. }\end{array}$ & & \\
\hline Aproximação teórica & $\begin{array}{l}\text { - Hofstede (1991); Tanure (2005; 2010); } \\
\text { Wood e Chu (2008) }\end{array}$ & - Godoy; Peçanha (2009) \\
\hline
\end{tabular}

Fonte: baseado em Godoy e Peçanha (2009); Hofstede (1991); Tanure (2005; 2010); Wood e Chu (2008).

No quadro, verificamos as principais diferenças entre a cultura nacional e a cultura de inovação. Nas relações institucionais, por exemplo, a alta distância hierárquica, postura paternalista do líder e de espectador dos liderados dificultam os processos participativos, assim como desencoraja a autonomia e o comportamento de inovação. Nas relações pessoais, na cultura de inovação é importante reconhecer e valorizar esforços e conquistas profissionais independentemente das relações de amizade estabelecidas. Os conflitos, na cultura brasileira, muitas vezes são marcados ou evitados pelo medo de errar ou pela necessidade de manter relações cordiais. Na cultura de inovação, o conflito pode ser uma forma desafiante de encontrar novas soluções. Em relação à comunicação, os processos informais e o modelo assimétrico são muito presentes na cultura brasileira devido às relações pessoais e institucionais baseadas na amizade e no poder. Para inovar, é preciso comunicação simétrica, assertividade, clareza e abertura para o diálogo constante. Em relação à flexibilidade, a adaptabilidade e a criatividade são elementos da cultura brasileira que favorecem a inovação e, se bem gerenciadas, colaboram para obtenção de resultados positivos e o crescimento da organização. A cultura de inovação também tem como característica a orientação para o mercado e o foco nos resultados. Cada vez mais as empresas brasileiras tendem a reconhecer a necessidade da adoção de padrões operacionais e gerenciais superiores para se tornarem competitivas e inovadoras.

\section{METODOLOGIA UTILIZADA}

Além da pesquisa bibliográfica, o presente estudo baseou-se em uma análise documental de manuais de conduta e ética de algumas empresas brasileiras listadas como as mais inovadoras no Ranking Forbes 2013. A escolha por conveniência ocorreu pelo destaque que as empresas ocuparam no ranking e por serem grandes empresas internacionalizadas e consolidadas no mercado brasileiro com mais de quarenta anos de atuação. No Quadro 4, apresentamos um perfil resumido das empresas selecionadas: 
Quadro 04 - Perfil das empresas pesquisadas.

\begin{tabular}{|c|c|c|c|c|}
\hline Empresa & Posição & Segmento de atuação & $\begin{array}{c}\text { Tempo de } \\
\text { mercado }\end{array}$ & Número de funcionários \\
\hline Natura & $10^{\text {ạ }}$ & $\begin{array}{r}\text { Higiene pessoal, perfumaria } \\
\text { e cosméticos }\end{array}$ & 45 & $\begin{array}{c}7 \text { mil colaboradores e mais de } 1.5 \\
\text { milhões de consultoras (2013) }\end{array}$ \\
\hline BRF & 39 ạ & $\begin{array}{c}\text { Carnes, alimentos processados, } \\
\text { lácteos, margarinas, massas, } \\
\text { pizzas e vegetais congelados }\end{array}$ & 80 & Cerca de 110 mil funcionários (2014) \\
\hline Ultrapar & $55^{a \underline{a}}$ & $\begin{array}{c}\text { Distribuição de combustíveis e } \\
\text { GLP (gás liquefeito de petróleo) }\end{array}$ & 77 mil funcionários diretos (2014) \\
\hline
\end{tabular}

Fonte: Natura, 2013a; BRF, 2014; Ultrapar, 2014.

Verificamos, noquadro, quea Natura, empresaqueatua nosetor debeleza, apresentamenor temponomercadoemelhorcolocação no Ranking Forbes de inovação, mesmo sendo a empresa com menor número de funcionários diretos. Internacionalmente, a Natura opera no Brasil e em mais sete países: Argentina, Chile, Peru, México, Colômbia, França e Nova York (Natura, 2013a).

A empresa BRF atua no setor de alimentos e das três organizações analisadas é a mais antiga no mercado com oitenta anos de história e o maior número de funcionários (110 mil). No Ranking Forbes de inovação, ocupou a 39a posição. Além do mercado brasileiro, mantém nove unidades industriais na Argentina e duas na Europa (Inglaterra e Holanda), além de dezenove escritórios comerciais para atendimento a mais de 120 países dos cinco continentes (BRF, 2014).

A Ultrapar é uma grande organização brasileira que atua no setor de varejo e distribuição de combustíveis por meio da Ultragaz, Ipiranga e Extrafarma. Ocupou a 55a posição no ranking Forbes de inovação e mantém operações internacionais com unidades industriais nos Estados Unidos, no Uruguai, no México e na Venezuela e escritórios comerciais na Argentina, na Bélgica, na China e na Colômbia (Ultrapar, 2014).

Em relação aos códigos de conduta e ética, selecionamos estes documentos por considerá-los objetos de registros das normas e dos valores organizacionais e como dispositivos comunicativos na construção da cultura organizacional. Também são importantes ferramentas normativas e formativas que contribuem para direcionar as práticas organizacionais. 0 fato de as organizações atuarem em diferentes segmentos também possibilitou analisar as especificidades de cada código em relação ao tipo de organização.

Lançado em agosto de 2013, o código de conduta da Natura surgiu da revisão e atualização dos "Princípios de relacionamento" elaborados no ano 2006. No documento estão descritos os compromissos do colaborador e diretrizes relacionadas aos seguintes aspectos: a) conflitos de interesses; b) relacionamento e ambiente de trabalho; c) uso da informação além de esclarecimentos sobre a gestão da conduta, os canais de diálogo e o comitê de ética. No final, há um glossário que explica alguns termos técnicos utilizados no decorrer do documento. 
O código de ética e conduta da BRF foi aprovado em 2012 e sua última atualização aconteceu em novembro de 2013. 0 documento apresenta o objetivo e abrangência do código, os valores e princípios éticos da organização, as políticas de gestão, as diretrizes de relacionamento com os diversos públicos com as quais a organização se relaciona e as diretrizes de conflito de interesses. Trata também das diretrizes sobre informações financeiras e registros contábeis, explica a gestão e o desenvolvimento da ética e conduta, informa sobre a aprovação, vigência e divulgação do código e disponibiliza como anexos modelo do termo de compromisso e adesão que deve ser assinado pelos funcionários, além de um glossário técnico ao final do documento.

Adotado em abril de 2004, 0 código de ética da Ultrapar teve sua terceira revisão realizada em junho de 2009 . 0 documento apresenta os objetivos e a abrangência do código de ética. Também detalha os princípios éticos que devem ser seguidos por todos os profissionais da organização, os deveres em relação a práticas de trabalho, observância da legislação, obediência aos princípios de defesa da concorrência, garantia da qualidade e do bom uso da informação, uso e divulgação de informação que não seja pública, conflito de interesse e penalidades.

Observamos nas três empresas que a utilização dos códigos de éticas são práticas recentes nas organizações brasileiras, conforme ressalta Humberg (2002). Nos três documentos percebemos a preocupação em relação a conflitos de interesse, uso de informações e relacionamento no ambiente do trabalho. Essas preocupações afetam diretamente a cultura organizacional e podem ou não reforçar traços da cultura nacional ou da cultura de inovação.

Para verificar a qualidade de um documento, Joan Scott (apud Flick, 2009) considera relevante analisar a autoria (quem produziu o documento), o acesso aos documentos e o contexto em que eles são produzidos e utilizados. Nesse sentido, entendemos que os códigos de ética são documentos oficiais produzidos pelas próprias organizações, alinhados exclusivamente com as suas políticas de governança. Entre os objetivos listados nos códigos de éticas estão: reduzir a subjetividade das interações, formalizar a conduta; garantir comportamento ético; garantir práticas de sustentabilidade. Os códigos analisados se aplicam a uma variedade de públicos, como os colaboradores, administradores e conselheiros, para adoção de um padrão de relacionamento interno e externo com acionistas, clientes, sindicatos, parceiros, fornecedores, concorrentes, governo, comunidade e sociedade. Esses documentos também são de acesso público, já que estão disponíveis no site das organizações para que qualquer pessoa possa consultá-los.

Em relação ao discurso e à linguagem, nos códigos analisados predomina o tom imperativo e normativo: "você deve cumprir"; "você não pode usar"; "cada profissional deve se preocupar"; "não é permitido"; etc. Também verificamos que a Natura, de forma mais pessoal, utiliza o termo "você" para dirigir-se aos públicos, sendo que as duas outras organizações mantêm uma linguagem mais impessoal, com o uso de termos como "cada profissional" e "os funcionários da BRF". Em geral, nos códigos estão previstas medidas disciplinares em caso de violação dos princípios éticos, inclusive para falhas de supervisão, e demissão e processos judiciais em caso da violação de leis. Segundo Daineze (2004), podemos afirmar que os documentos estão mais próximos de serem instrumentos normatizadores de conduta do que ferramentas formadoras de princípios.

\section{ANÁLISE DOS RESULTADOS OBTIDOS}

Para a análise dos traços culturais presentes nos códigos de conduta e ética das três empresas selecionadas utilizamos as categorias culturais definidas no Quadro 3. Para cada categoria foi analisado se a organização inibe, incentiva ou não faz referência aos traços das características da cultura nacional ou da cultura de inovação. 0 Quadro 5 apresenta os resultados da análise. 
Quadro 5 - Traços para a cultura nacional e de inovação nos códigos de conduta e ética

\begin{tabular}{|c|c|c|c|c|c|c|}
\hline \multirow[b]{2}{*}{ CATEGORIA } & \multicolumn{2}{|c|}{ NATURA } & \multicolumn{2}{|c|}{ BRF } & \multicolumn{2}{|c|}{ ULTRAPAR } \\
\hline & Cultura nacional & $\begin{array}{l}\text { Cultura de } \\
\text { inovação }\end{array}$ & Cultura nacional & $\begin{array}{l}\text { Cultura de } \\
\text { inovação }\end{array}$ & Cultura nacional & $\begin{array}{l}\text { Cultura de } \\
\text { inovação }\end{array}$ \\
\hline $\begin{array}{c}\text { Relações } \\
\text { institucionais }\end{array}$ & Não faz referência & Incentiva & Não faz referência & Incentiva & Inibe & Incentiva \\
\hline Relações pessoais & Inibe & Incentiva & Inibe & Não faz referência & Inibe & Não faz referência \\
\hline $\begin{array}{l}\text { Gestão de } \\
\text { conflitos }\end{array}$ & Inibe & Incentiva & Inibe & Incentiva & Inibe & Incentiva \\
\hline Comunicação & Não faz referência & Incentiva & Inibe & Incentiva & Não faz referência & Não faz referência \\
\hline Flexibilidade & Não faz referência & Incentiva & Não faz referência & Incentiva & Não faz referência & Não faz referência \\
\hline $\begin{array}{c}\text { Orientação para } \\
\text { resultados }\end{array}$ & Incentiva & Incentiva & Incentiva & Incentiva & Incentiva & Incentiva \\
\hline
\end{tabular}

Fonte: elaborado pelas autoras.

No quadro, verificamos que as organizações que mais incentivam traços da cultura de inovação, são também aquelas que apresentam melhor colocação no Ranking Forbes 2013das empresas mais inovadoras, demonstrando o potencial dos códigos de ética para a comunicação dos valores organizacionais. Também constatamos que, quanto maior a preocupação das organizações em inibir condutas relacionadas a traços culturais brasileiros como personalismo (relações pessoais) e aproveitamento das relações de poder para obtenção de favores de subordinados (relações institucionais), menor é a posição da empresa no Ranking Forbes 2013. Dessa forma, notamos que organizações que utilizam os seus códigos como reforçadores positivos para estimular comportamentos desejáveis são mais inovadoras que aquelas que utilizam reforçadores negativos com função de fazer com que os indivíduos apenas evitem comportamentos indesejáveis. A seguir, apresentamos de forma detalhada cada categoria analisada.

\section{Relações institucionais}

As relações institucionais referem-se à forma como é organizado e distribuído o poder na organização e a relações formais estabelecidas entre líderes e liderados.

A Natura (2006) menciona nos seus princípios de relacionamento a importância do trabalho em equipe e da diversidade. "Acolhemos e estimulamos a diversidade (...). Valorizamos o trabalho em equipe (...)". No código de ética, a Natura (2013b), apoia o empreendedorismo de seus funcionários: "apoiamos o empreendedorismo de nosso time".

A BRF declara que "considera a capacidade técnica, a experiência profissional e a competência de integrar-se em grupos de trabalhos (...)". Identificamos aqui traços da cultura da inovação, já que a empresa preza pelo incentivo do trabalho em equipe e pela valorização da competência técnica para o desenvolvimento de grupos de trabalho (Godoy; Peçanha, 2009).

A Ultrapar também ressalta a necessidade de considerar as qualificações profissionais como base de decisões e adverte os funcionários para "manter comportamento que não deixe espaço para discriminações ou constrangimentos, incluindo assédio 
moral e sexual, em particular na relação chefe-subordinado", demonstrando uma preocupação em inibir relações de abuso de poder. Conforme a literatura existente, "a hierarquia e a concentração de poder continuam como fortes dimensões na sociedade brasileira" (Tanure, 2010, p. 42). Somadas ao paternalismo, geram a postura de espectador e falta de questionamento por parte dos indivíduos, o que pode gerar situações de constrangimentos e submissão. Nesse sentido, verificamos que a tendência predominante é que as organizações passem a incentivar a gestão participativa a partir de orientações de comportamentos proativos e de maior comprometimento coma equipe de trabalho, conforme destaca um dos princípios da BRF: "desenvolvimento de pessoas, fundamental para sustentar o crescimento".

\section{Relações pessoais}

As relações pessoais referem-se à forma como indivíduos se relacionam no cotidiano da empresa. Presente na gestão das organizações brasileiras, o personalismo é o ponto mais claramente referenciado pelos códigos de conduta. São muitas as recomendações e até mesmo advertências sobre esse traço cultural.

0 código de ética da Natura (2013b) declara que "é permitida a relação de parentesco e o relacionamento afetivo entre colaboradores, desde que não haja qualquer nível de subordinação hierárquica, influência de decisão de gestão e processos". A BRF estabelece normas que coíbem a contratação de familiares e parentes: "Não é permitida a contratação de funcionários e coparentes que não seja por processo seletivo promovido pela Área de Recursos Humanos". A Ultrapar orienta para a recusa de gratificações no exercício das atividades profissionais

As características marcantes do personalismo (Wood; Chu, 2008) estão no fato de as pessoas buscarem relacionamentos pessoais no trabalho e os considerarem mais importantes do que as competências técnicas, ou buscar benefícios pessoais em detrimento de coletivos. Nesse sentido, as três empresas buscam inibir tais comportamentos com normas bem definidas sobre os relacionamentos entre pares que são estabelecidos no ambiente organizacional.

Também identificamos aspectos que demonstram a preocupação da organização com o reconhecimento e esforços de conquistas dos funcionários: "Você pode sugerir fornecedores (...), mesmo que sejam seus parentes, desde que não tenha qualquer participação no processo de tomada de decisão sobre a contratação" (Natura, 2013b).

Outro ponto interessante são normas que buscam regulamentar práticas do "jeitinho brasileiro" de buscar obter privilégios profissionais a partir das relações pessoais (Tanure, 2005; 2010), de forma a transformá-las em práticas legais dentro dos limites organizacionais: "Você pode desempenhar as atividades paralelas que desejar, desde que não prejudiquem o seu rendimento, que sejam realizadas fora do horário de trabalho (...) e que não conflitem com os negócios, interesses e setor de atuação da empresa" (Natura, 2013b).

Verificamos que os traços da cultura da inovação nas relações pessoais ainda é uma prática que pode ser mais bem explorada nos códigos de ética das organizações, indicando possibilidades de ajustar os comportamentos culturais nacionais aos padrões culturais organizacionais.

\section{Gestão de conflitos}

A gestão de conflitos refere-se à forma como se administram as negociações, os conflitos e a tomada de decisão. A aversão a conflitos é um traço da cultural nacional divergente da cultura de inovação que demanda alta tolerância a conflitos. Esse traço 
brasileiro é fruto da supervalorização dos relacionamentos pessoais, o que resulta na dificuldade de dizer não, de fornecer feedback assertivo e no desconforto de tratar abertamente os conflitos. Verificamos nos documentos das três organizações uma significativa preocupação com a gestão de conflitos, tanto em inibir situações de conflitos abertos e embates pessoais por meio da instituição de comitês de ética, quanto em incentivar e valorizar o trabalho com a diversidade de pessoas.

As três organizações orientam os públicos a se reportaremaos comitês de ética em situações de conflitos: “Éde responsabilidade de cada profissional notificar imediatamente o comitê de ética (...) sobre quaisquer situações potencialmente contrárias a princípios éticos, ou que sejam ilegais, irregulares ou duvidosas" (Ultrapar, 2009). A Natura apresenta uma ouvidoria como um canal para a gestão da conduta: "Sempre que forem identificados casos de descumprimento do código, eles devem ser reportados à ouvidoria para que recebam tratamento adequado" (Natura, 2013b). A BRF apresenta os canais de denúncias, orientando que "as denúncias devem ocorrer quando o funcionário ou terceiro colaborador tiver conhecimento dos dados ou fatos concretos que estejam beneficiando alguém, em prejuízo de outros ou da própria companhia; ou de comportamentos que se enquadrem em algumas das hipóteses vedadas por esse código de ética e conduta" (BRF, 2013).

Em relação à tolerância ao conflito eao incentivo de trabalho desafiante eem equipe (traços da cultura de inovação), identificamos as seguintes declarações nos documentos da Natura: "Valorizamos a diversidade de nossa equipe" (Natura, 2013b); "Aprendemos por meio dos nossos relacionamentos. Garantimos que em nossas relações haja espaço para o surgimento de ideias novas e criativas" (Natura, 2006). A BRF incentiva a cultura da inovação em relação à gestão de conflitos quando declara: "Estimulamos a integração e o respeito a diferentes culturas e acreditamos que a diversidade é uma vantagem competitiva para os nossos negócios" (BRF, 2013). De maneira mais tímida, em um dos princípios do código de ética da Ultrapar, verificamos a valorização da diversidade e a preocupação em manter um trabalho de equipe unido e coeso: "Pautar a relação chefe-colaborador pelo respeito mútuo, honestidade e educação, construindo-se um clima profissional sólido e de coesão organizacional" (Ultrapar, 2009).

\section{Comunicação}

A comunicação refere-se à maneira como acontecem as interações e trocas de informações significativas na organização. No âmbito da cultura nacional, a comunicação é marcada pela comunicação assimétrica, informal e prolixidade das mensagens. Não identificamos nos códigos de ética das empresas analisadas menções em relação a inibição ou incentivo a essas características. No entanto, no âmbito da cultura da inovação, verificamos em duas organizações analisadas grande incentivo para a construção de um espaço de expressão de opiniões e de prática da comunicação simétrica de mão dupla (Grunig et al., 2011), com o diálogo aberto com todos os públicos e principalmente com o reconhecimento de que as opiniões possam ser incorporadas pela organização. De maneira mais acentuada, a Natura declara: "Sabemos que o diálogo e a troca de informações entre nossos colaboradores e áreas são fundamentais para a evolução do nosso negócio" (Natura, 2013b). Nos princípios de relacionamentos, a Natura também enfatiza "Buscamos estabelecer diálogo aberto com todos os públicos. Queremos ouvir, valorizamos as opiniões recebidas e procuramos incorporar tudo aquilo que possa nos fazer evoluir". A BRF inclui, como um dos seus princípios, "relacionamento ético e comunicação fluida e transparente com todas as partes interessadas".

Considerando que a comunicação é o processo que permeia todas as áreas da organização e que os códigos de éticas são comunicadores dos princípios da organização, entendemos que eles podem colaborar para tornar o processo de comunicação mais transparente e os relacionamentos, mais sinceros e éticos. De fato, mais do que estabelecer princípios para a comunicação transparente e simétrica, é necessário oferecer condições no ambiente de trabalho para que o diálogo faça parte do ambiente. 
Por isso, quanto mais os códigos de ética ou instrumentos de comunicação institucionais forem produzidos e utilizados como ferramentas didáticas e educativas na organização, maior será a possibilidade de a comunicação simétrica de mão dupla tornar-se uma realidade empresarial.

Consideramos, portanto, que as normas são fundamentais para iniciar uma mudança de comportamento na organização. Também, quanto mais os funcionários e públicos da organização participam do processo de formulação dessas regras, maior será a possibilidade de elas serem praticadas no cotidiano da empresa. A Natura e a BRF incentivam os públicos a dar sugestões e realizar críticas em relação ao código de conduta e ética para reformulações futuras.

\section{Flexibilidade}

A flexibilidade está relacionada à forma como as pessoas e a organização lidam com as mudanças do ambiente interno e externo. Considerando o lado positivo da flexibilidade relacionada a adaptabilidade e criatividade (Tanure, 2010), verificamos que a Natura e a BRF mencionam nos seus códigos de ética a valorização da criatividade e da inovação. Nos princípios de relacionamento, a Natura declara: "Propiciamos um ambiente favorável para inovação. Garantimos que em nossas relações haja espaço para 0 surgimento de ideais novas e criativas" (Natura, 2006). A BRF ressalta que no seu processo de gestão considera "desenvolvimento e aplicação de tecnologias que garantam inovação, produtividade, competitividade e excelência operacional" (BRF, 2013). Dada a conotação negativa que a flexibilidade pode apresentar, quando relacionada a um comportamento amador (Wood; Chu, 2008), consideramos necessária maior atenção a esse aspecto, já que os benefícios da criatividade e da adaptabilidade podem ser sufocados em vez de se transformarem em poderosos fatores de diferencial competitivo das empresas brasileiras.

\section{Orientação para resultados}

A orientação para resultados refere-se à forma como a organização planeja processos, administra o tempo e lida com o risco. 0 alto nível de controle de incerteza (Hofstede, 1991) é um dos traços da cultura nacional e, quanto mais normatizadores são os códigos de conduta e ética, maior é o seu potencial de controle da incerteza. Considerando que o reconhecimento da importância da adoção de padrões operacionais e gerenciais superiores tem sido uma característica marcante da cultura nacional, identificamos que nos códigos de ética das três organizações há uma preocupação com tais aspectos.

"Garantimos um bom ambiente de controles internos, que compreende um conjunto de políticas, normas e procedimentos" (Natura, 2006). A BRF, no seu código de ética, ressalta que alta performance é uma busca permanente da empresa, assim como a qualidade em produtos e excelência em processos. 0 código de ética da Ultrapar destaca a necessidade de "zelar pelo uso competente dos bens e recursos da empresa, para que não ocorram danos, manejo inadequado, perdas, frutos ou retirada sem prévia autorização" (Ultrapar, 2009).

Por outro lado, também verificamos nos códigos de ética a orientação para o mercado e foco nos resultados, características marcantes da cultura da inovação. A Natura (2006) enfatiza: "Criamos produtos inovadores, que atendam às necessidades funcionais dos nossos consumidores, promovam o seu bem-estar e sejam um instrumento de ampliação de consciência". 0 código de ética da BRF (2013) estabelece como um dos princípios gerais o espírito de inovação constante. A Ultrapar (2009) incentiva os profissionais que atuam na organização a trabalharem "na busca da maximização do valor da companhia". Considerando 
que o alto nível de controle de incerteza pode burocratizar e retardar os processos de inovação, a orientação para os resultados deve ser incentivada no sentido de reconhecer padrões operacionais e gerenciais superiores que tornem a empresa mais ágil e mais preparada para atuar em ambientes mais vulneráveis e incertos. Criar normas que não limitem a agilidade dos processos e colaborem na tomada de decisão dos públicos e no desenvolvimento de novas ideias ainda é um desafio a ser superado por muitas organizações. Regras e normas claras são importantes para a orientação para resultados, porém é preciso ações conjuntas de desenvolvimento e formação de pessoal, para que tais normas sejam transformadas em práticas assertivas e criativas.

\section{CONSIDERAÇÕES FINAIS}

Estimular a cultura de inovação é um dos grandes desafios de gestão no Brasil e uma necessidade para tornar as empresas mais competitivas e globais. Este estudo teve como objetivo identificar os traços da cultura nacional e de inovação em três códigos de conduta e ética de empresas brasileiras mais inovadoras segundo o Ranking Forbes 2013. Como comunicadores organizacionais, verificamos que os códigos de ética podem contribuir para a formação da cultura de inovação. Nas empresas analisadas, identificamos que as empresas que mais incentivam aspectos da cultura de inovação são também aquelas com melhor colocação no Ranking Forbes.

A avaliação das normas ou orientações presentes nos documentos permitiu verificar que os códigos de ética inibem mais fortemente condutas relacionadas ao traço cultural do personalismo e que o tema inovação ainda é abordado de forma tímida. Em primeiro lugar, é preciso reconhecer que os códigos de ética se baseiam em modelos internacionais e no segmento de negócio da organização, não abordando, portanto, diretamente as questões referentes às características culturais nacionais. É possível que os códigos de conduta e ética que utilizam uma linguagem mais clara e próxima dos públicos a que se destinam provavelmente sejam produzidos pela organização em parceria com o setor ou agências de comunicação. Assim, os traços da cultura nacional poderiam ser trabalhados pelos profissionais de comunicação na elaboração desses documentos institucionais. Desta forma, estes seriam mais assertivos e estratégicos na orientação de determinado comportamento e, juntamente com programas mais extensos de comunicação e educação gerencial, poderiam estimular mudanças ou reforçar posturas necessárias para um ambiente mais produtivo, criativo e humanizado. Em segundo lugar, é preciso considerar a existência de subculturas e grupos com distintos traços culturais em uma mesma organização. Esses grupos podem ou não ser mais ou menos propensos a cultura de inovação.

Reconhecemos também os códigos de conduta e ética como importantes canais da cultura organizacional e um dos primeiros instrumentos de contato com novos colaboradores. Por isso, eles não devem ser entendidos como instrumentos de controle, mas sim como articuladores de um processo contínuo de busca de melhorias dos relacionamentos com os públicos da organização. Portanto, devem fazer parte de uma estratégia comunicacional mais ampla inserida no modelo de comunicação simétrica de mão dupla. A própria comunicação deve ser tema dos códigos de ética, de forma a incentivar maior interação, participação, transparência e colaboração entre os setores e membros da organização.

Indicamos também algumas limitações desta pesquisa: a) o caráter exploratório e qualitativo não permite realizar generalizações para o universo de empresas brasileiras, além de também estar sujeita às interpretações e subjetividade dos autores; b) sendo a amostra reduzida e a análise, apenas documental, o que se consegue é observar alguns indícios dos traços 
da cultura nacional e de inovação, uma vez que o setor, tamanho e segmento de negócios podem influenciar na estrutura dos códigos de ética, como também na sua aplicação. A análise do conteúdo presente nos documentos institucionais também pode ser mais detalhada e confrontada com outros discursos e conteúdos produzidos por outros atores sobre a organização.

Em cada categoria criada para análise dos documentos, identificamos aspectos interessantes para futuras pesquisas.

Quanto às relações institucionais, concluímos que existe uma tendência para incentivar os processos de gestão democrática e, como oportunidade de novas pesquisas, seria possível entender de que forma os processos de gestão democráticos são implementados e gerenciados na organização, assim como relacioná-los com os modelos de comunicação utilizado e 0 potencial inovador desse tipo de gestão.

Quanto às relações pessoais, ficou evidente a preocupação das organizações em inibir traços da cultura nacional relacionados ao "jeitinho brasileiro", ao personalismo e à obtenção e distribuição de privilégios baseado nas relações de amizade e de poder. É possível realizar novos estudos comparativos entre códigos de conduta e ética de organizações nacionais e estrangeiras para identificar semelhanças e diferenças no tratamento desse tema pelas organizações.

A gestão de conflitos também foi um tema muito presente nos códigos de conduta e ética das organizações analisadas. Percebemos a preocupação das organizações em instituir canais mediadores de conflitos. Um trabalho de formação em negociação para os colaboradores poderia contribuir para que os próprios funcionários pudessem gerenciar e resolver os conflitos entre pares. Uma pesquisa complementar por meio de entrevistas em profundidade com os responsáveis pela gestão de conflitos nas organizações poderia ajudar a mapear os tipos de conflitos mais comuns e de que forma estes interferem no trabalho em equipe e em processos de inovação.

A busca pela comunicação simétrica de mão dupla também foi uma preocupação identificada em dois códigos de ética analisados. No entanto, consideramos que as informações dos códigos de ética e conduta são insuficientes para concluirmos se o diálogo transparente está realmente presente nas relações da organização com seus públicos. Para futuras pesquisas, é possível utilizar as características da cultura nacional e da cultura de inovação para por meio de um questionário estruturado identificar com os colaboradores de cada organização o modelo de comunicação mais presente no cotidiano organizacional.

A flexibilidade foi um traço identificado nos códigos de conduta e ética de duas organizações analisadas. Consideramos relevante um levantamento complementar com alguns dos públicos da organização para entender de forma mais aprofundada de que maneira as pessoas lidam e são preparadas para lidar com as mudanças.

A orientação para resultados foi identificada nos códigos de ética das três organizações, sentido tanto no de controlar as incertezas e formalizar os processos operacionais, quanto de buscar a excelência e o atendimento das necessidades do mercado. Em relação a este aspecto, um estudo futuro para identificar se as normas burocratizam ou agilizam os processos de inovação.

Finalmente, consideramos que o estudo contribuiu para a sistematização de um quadro comparativo dos traços da cultura nacional e da cultura de inovação, estabelecendo categorias que podem ser utilizadas em novas pesquisas e com uma amostra mais representativa do universo de organizações brasileiras. 
Destacamos que a análise dos códigos de conduta e ética das organizações é um importante objeto de estudos qualitativos e de expressão dos valores compartilhados pela organização. Dessa forma, devem ser mais bem aproveitados para estimular a cultura de inovação e ressaltar traços da cultura nacional como diferenciais competitivos quando pertinente.

\section{REFERÊNCIAS}

AHMED, Pervaiz K. Culture and climate for innovation. European Journal of Innovation Management, v. 1, n. 1, p. 30-43, 1998.

BRF. Código de ética e conduta (2013). Disponível em <http://www.brasilfoods.com/ ri/siteri/web/conteudo_ pt.asp? idioma=0\&conta=28\&tipo=32167>. Acesso em: 28 ago. 2014.

Quem somos. (2014). Disponível em <http://brf-global.com/brasil/sobre-brf/quem-somos-nossa-historia>. Acesso em: 10 out. 2014.

DAINEZE, Marina do Amaral. Códigos de ética empresarial e as relações da organização com seus públicos. In: Responsabilidade social das empresas. a contribuição das Universidades. VIII. São Paulo: Peiropólis, 2004.

FERRARI, Maria Aparecida. A influência dos valores organizacionais na determinação da prática e do papel dos profissionais de relações públicas: estudo comparativo entre organizações do Brasil e do Chile. São Paulo, 2000. Tese (Doutorado em Ciências da Comunicação) - ECA-USP.

FINEP. Manual de Oslo: proposta de diretrizes para coleta e interpretação de dados sobre inovação tecnológica. 3.ed. OECD, Finep, 1997. Disponível em: <http://download.finep.gov.br/imprensa/manual_de_oslo.pdf>. Acesso em 28 dez. 2013.

FLICK, Uwe. Introdução à pesquisa qualitativa. 3. ed. Porto Alegre: Artmed / Bookman, 2009.

FORBES BRASIL. As empresas mais inovadoras do mundo - 2013. Disponível em < http://forbesbrasil.br.msn.com/listas/asempresas-mais-inovadoras-do-mundo\#image=11>. Acesso em: 28 ago. 2014.

GODOY, Renata Semensato Pereira de; PEÇANHA, Dóris Lieth Nunes. Cultura organizacional e processos de inovação: um estudo psicossociológico em empresa de base tecnológica. Bol. - Acad. Paul. Psicol., São Paulo, v. 29, n. 1, jun. 2009, p. 14263. Disponível em: <http://pepsic.bvsalud.org/scielo.php? script=sci_arttext\&pid=S1415-711X2009000100012\&lng=pt\&nrm= iso>. Acesso em 28 dez. 2013.

GRUNIG, James E. (Org.) Excellence in public relations and communication management. New Jersey: Lawrence Erlbaum, 1992.

GRUNIG, James E.; FERRARI, Maria Aparecida; FRANÇA, Fábio. Relações públicas:teoria, contexto e relacionamento. 2. ed., São Caetano do Sul, SP: Difusão Editora, 2011.

HOFSTEDE, Greert. Culture's Consequences: international differences in workrelated values. London. Sage Publications, 1980. 
Cultural Dimensions in Management and Planning. Asia Pacific Journal of Management. Janeiro, 1984.

Cultures and organizations: software of the mind. London: McGraw-Hill, 1991.

HUMBERG, Mario Ernesto. Ética na política e na empresa:12 anos de reflexão. São Paulo: CLA, 2002.

MARTINS, Ellen C.; TERBLANCHE Fransie. Building organizational culture that stimulates creativity and innovation. European Journal of Innovation Management, v. 6, n. 1, 2003.

MAVONDO, Felix T.; FARRELL, Mark. Cultural orientation: its relationship with market orientation, innovation and organizational performance. Management Decision, v. 41, n. 3, p. $241-249,2003$.

MOTTA, Fernando C. Prestes; CALDAS, Miguel P. Cultura organizacional e cultura brasileira. São Paulo: Atlas, 1997.

NATURA. Princípios de relacionamento (2006). Disponível em: <http://natura. infoinvest.com.br/fck_temp/10_7/file/Principios_ Relacionamento.pdf>. Acesso em: 28 ago. 2014.

Relatório de Administração 2013a. Disponível em: <http://natu.infoinvest.com.br/ptb/4876/Natura_GRI_ Completo_20140328final.pdf>. Acesso em: 10 out. 2014.

Código de conduta, versão 1, agosto 2013b. Disponível em <http://natu.infoinvest.com.br/ptb/104/CdigodeConduta. pdf >. Acesso em: 10 out. 2014.

STRINGER, Robert. (2000). How to manage radical innovation. California Management Review, n. 2, p. 1-11, 2000.

TANURE, Betania. Gestão à brasileira. 2 ed. São Paulo, Atlas, 2005.

. Gestão à brasileira: somos ou não diferentes? Uma comparação com América Latina, Estados Unidos, Europa e Ásia. 3. ed. São Paulo: Atlas, 2010.

TANURE, Betania; PRATES, Marco Aurélio Spyer. 0 estilo brasileiro de administrar: sumário de um modelo de ação cultural brasileiro com base na gestão empresarial. In: Fernando C. Prestes Motta; Miguel P. Caldas;. (Org.). Cultura organizacional e cultura brasileira. São Paulo: Atlas, 1997, v., p. 55-69

THE GLOBAL COMPETITIVENESS REPORT 2013-2014. World Economic Forum, 2013. Disponível em: <http://www3.weforum. org/docs/WEF_Global CompetitivenessReport_2013-14.pdf>. Acesso em: 18 dez. 2013.

THE GLOBAL INNOVATION INDEX 2013. Cornell University, Insead, and the World Intellectual Property Organization (Wipo), 2013. Disponível em:<http://www.globalinnovationindex.org/content.asx?page=gii-full-report-2013>. Acesso em 18 dez. 2013.

ULTRAPAR. Código de ética (2009). Disponível em <http://www.ultra.com.br /ri/Show.aspx?ldMateria=B2F02iusnX5FehuN/ XaJWw==>. Acesso em: 28 ago. 2014. 
Perfil. Disponível em: <http://www.ultra.com.br/show.aspx?idCanal= EICAyAnog/4500ziHZ9TYQ==>. Acesso em: 10 out. 2014.

WOOD JR., Thomaz; CHU, Rebeca Alves. Cultura organizacional brasileira pós-globalização: global ou local? Revista de Administração Pública-RAP, Ebape FGV, Rio de Janeiro, 2008.

Artigo recebido em 08.09.2014 e aprovado em 22.10.2014. 